\title{
Differential antibacterial activities of fusiform and oval morphotypes of Phaeodactylum tricornutum (Bacillariophyceae)
}

\author{
ANDREW P. DESBOIS ${ }^{1}$, MIKE WALTON AND VALERIE J. SMITH \\ Scottish Oceans Institute, Gatty Marine Laboratory, School of Biology, University of St Andrews, Fife, Scotland, UK, \\ ${ }^{1}$ Present address: Biomedical Sciences Research Complex, School of Biology, University of St Andrews, Fife, Scotland, UK
}

\begin{abstract}
The diatom, Phaeodactylum tricornutum is a common inhabitant of inshore waters and can exist in different morphotypes that are thought to be adapted for survival in different habitats. Despite this diatom being widely used for physiological and genetic studies of microalgae, little is known about biochemical or physiological differences between the cell morphotypes. The present study was aimed at comparing differences in the antibacterial properties of the fusiform and oval morphotypes, the dominant cell types found in laboratory cultures of most strains of $\mathrm{P}$. tricornutum. In cultures differing in proportions of fusiform and oval cells, there is a significant and positive correlation between the proportion of cells in the fusiform morphotype and the antibacterial activity of cell extracts. Extracts prepared from cultures enriched for fusiform cells ( 76\%) show greater antibacterial activity against the Gram-positive bacterium, Staphylococcus aureus, than those prepared from pure (10o\%) oval cultures. Thus fusiform cells contain greater antibacterial activity per cell compared to the ovals. Gas-liquid chromatographic analyses of the extracts reveal that those from enriched fusiform populations contain significantly greater levels of the free fatty acids, eicosapentaenoic acid (EPA), hexadecatrienoic acid (HTA) and palmitoleic acid (PA) than the pure oval cell cultures. These free fatty acids from P. tricornutum have been previously shown by us to have potent antibacterial activity against $\mathrm{S}$. aureus. Free fatty acids, released from damaged microalgal cells, defend the microalgal population against grazing predators but, here, we suggest that these free fatty acids could also act against pathogenic bacteria in the vicinity of the algae. As cell extracts from the fusiform cells contain greater quantities of these fatty acids, fusiform cells may have greater potential than the ovals for this type of protection.
\end{abstract}

Keywords: morphology, diatom, fatty acid, antimicrobial, phytoplankton, plasticity

Submitted 20 November 2008; accepted 21 September 2009; first published online 10 February 2010

\section{INTRDDUCTION}

The pennate diatom, Phaeodactylum tricornutum Bohlin, lives in brackish and marine waters worldwide (De Martino et al., 2007; Tesson et al., 2009) and because it is easy to culture (Hayward, 1968) it has become a popular model for studies of microalgal physiology and biochemistry. Its prominence as a 'model' diatom has led to the publication of the complete genome sequence and, to date, it is one of only two diatoms to receive such complete genetic analysis (Bowler et al., 2008).

A feature of $P$. tricornutum is that it exhibits multiple morphotypes distinguishable by their shape. In laboratory culture the more common morphotypes are the oval-shaped and fusiform types (Lewin et al., 1958; Hayward, 1968; De Martino et al., 2007) although triradiate, intermediary and other unusual forms may also occur depending on the culture conditions and strain (Wilson, 1946; Coughlan, 1962; Borowitzka et al., 1977). These morphs are widely believed to represent phenotypic adaptations that favour survival in a changeable

Corresponding author:

V.J. Smith

Email:vjs1@st-andrews.ac.uk environment (Morales et al., 2002; De Martino et al., 2007; Bartual et al., 2008; Tesson et al., 2009). In the inshore waters where $P$. tricornutum is found, conditions that change quickly include light availability, nutrient inputs from adjacent land, water movement, and the presence of predators and habitable surfaces. It is well documented that the oval morphotype tends to occur on surfaces (Lewin et al., 1958; Hayward, 1968; Gutenbrunner et al., 1994; Tesson et al., 2009) and seems to dominate under conditions of stress or sub-optimal growth conditions (De Martino et al., 2007). The oval cells are motile, have siliceous valves and can produce exopolysaccharides; features that may help protect them when conditions are hostile (Lewin et al., 1958; Iwasa \& Shimizu, 1972; Borowitzka \& Volcani, 1978; Marsot \& Houle, 1989; Hamm et al., 2003; Reynolds, 2007; Francius et al., 2008). By contrast, the fusiform morphs have an elongated spindle shape and possess intracellular vacuoles that provide buoyancy (Lewin et al., 1958; Borowitzka \& Volcani, 1978). They are non-motile, lack siliceous valves and do not produce exopolysaccharides (Lewin et al., 1958; Borowitzka \& Volcani, 1978; Marsot \& Houle, 1989; Francius et al., 2008). Fusiform cells favour planktonic growth conditions and so often dominate over ovals 
in suspension cultures (Lewin et al., 1958; Hayward, 1968; Marsot \& Houle, 1989; Gutenbrunner et al., 1994). Triradiate forms, as their name suggests, have a 3-rayed appearance and, like the fusiforms, have no siliceous valves and are non-motile (Borowitzka \& Volcani, 1978; De Martino et al., 2007). Triradiates are found only rarely in laboratory cultures although suspension cultures of certain P. tricornutum strains (e.g. NEPCC640) may often contain a high proportion of cells in this morphotype (De Martino et al., 2007). In other respects the various morphotypes share similar internal structures when examined at the ultrastructural level (Borowitzka \& Volcani, 1978).

Given that the biology of $P$. tricornutum has been so extensively studied, it is surprising that so few investigations have been made of the physiological and biochemical differences between the morphotypes. The present work was undertaken to evaluate differences in the antibacterial capability between the two cell types, oval and fusiform, that occur most often in laboratory culture. Antibacterial activity was studied because prokaryotes represent a major group of competitors for microalgae in terms of space and resources and could also pose a threat as intracellular or epibiont parasites or direct pathogens (Cole, 1982; Imai et al., 1993; Mayali \& Azam, 2004). Methanol extracts of laboratory grown cultures of $P$. tricornutum are known to have growth inhibitory effects in vitro against Gram-positive and Gram-negative bacteria of marine or non-marine origin (Duff et al., 1966; Kellam \& Walker, 1989; Desbois et al., 2008, 2009). We have shown that certain unsaturated free fatty acids are responsible for the bactericidal properties of $P$. tricornutum methanol extracts, namely eicosapentaenoic acid (C20:5 n-3; EPA) (Desbois et al., 2009), (6Z, 9Z, 12Z)-hexadecatrienoic acid (C16:3 n-4; HTA) and palmitoleic acid (C16:1 n-7; PA) (Desbois et al., 2008). In this paper, therefore, we compare the antibacterial activities and fatty acid compositions of cell extracts derived from cultures highly enriched with either oval or fusiform cells. This makes it possible to test whether biochemical differences exist between the morphs and whether or not these could have functional benefits that aid survival against potential pathogens or competitors.

\section{MATERIALS AND METHODS}

\section{Reagents and micro-organisms}

Unless stated otherwise HPLC-grade reagents (or the highest grade available) and culture media were purchased from Sigma Aldrich Ltd (Poole, Dorset, UK) and ultra pure deionized water (Option 3; Elga, High Wycombe, Bucks, UK) was used throughout. All equipment, solutions and culture media were sterilized by autoclaving at $121^{\circ} \mathrm{C}$ for 15 minutes unless stated otherwise. Axenic Phaeodactylum tricornutum SAG1090-6 was purchased from the Experimental Phycology and Culture Collection of Algae at the University of Göttingen. Staphylococcus aureus SH10oo was kindly gifted by Professor Simon Foster (Department of Molecular Biology and Biotechnology, University of Sheffield).

\section{Mixed morphotype cultures}

As the production of pure cultures of oval and fusiform cells under identical growth conditions from a 'starter clone' is difficult, the first experiment compared the antibacterial activities of methanol extracts from $P$. tricornutum cultures differing in proportions of oval and fusiform cells. This indirect and correlative approach allowed us to compare bactericidal vigour without growing the two morphotypes under different nutrient or other culture conditions. The algae were grown axenically in $470 \mathrm{ml}$ transparent polycarbonate centrifuge bottles (VWR, Lutterworth, Leics, UK) with rubber stoppers ( $(40.5 \mathrm{~mm}, 2$-hole; Fisher Scientific, Loughborough, Leics, UK) at $20^{\circ} \mathrm{C}$. Each bottle contained $300 \mathrm{ml}$ modified enriched seawater, artificial water (ESAW) medium (Harrison et al., 1980) altered to use half-strength base solutions with full-strength nutrient enrichment for enhanced growth rate (data not shown). Filter-sterilized air $(0.22 \mu \mathrm{m}$, PFTE; Sartorius AG, Göttingen, Germany) was supplied to each bottle at $2.41 \mathrm{~min}^{-1}$ with light $\left(25-45 \mu \mathrm{mol} \mathrm{s}^{-1} \mathrm{~m}^{-2}\right)$ supplied by four cool white fluorescent tubes $\left(\mathrm{F}_{1} 8 \mathrm{~W} / 33\right)$ operating a 14:10 h light:dark regime. Each bottle was inoculated $5 \% \mathrm{v} / \mathrm{v}$ with a stationary phase culture containing a mixture of fusiform and oval cells. Each bottle was topped up with sterile water to counter small evaporative losses every 48 hours and the cultures were allowed to establish their own unique mix of oval and fusiform cells. After ten days' growth, cell density and the percentage of each morphotype in the algal population were determined for each culture from at least triplicate cell counts by light microscopy using an Improved Neubauer haemocytometer. A total of 51 cultures were prepared.

\section{Enriched morphotype cultures}

As triradiate cells were not seen in any of the mixed cultures from above, only oval and fusiform cells were enriched in cultures for more detailed studies. These were grown in shakeflasks containing $150-300 \mathrm{ml}$ sterile modified ESAW medium (25-45 $\mu \mathrm{mol} \mathrm{s}^{-1} \mathrm{~m}^{-2}$; 14:10 h light:dark; $\left.20^{\circ} \mathrm{C}\right)$. The enriched cultures were obtained by repeated sub-culture from those flasks showing a predominance of either oval or fusiform morphs until the highest possible enrichment of each was reached. Whilst it was possible to produce flasks containing $100 \%$ oval cells, the average enrichment achieved with the fusiform cells was $75.9 \pm 4.1 \%$ (mean \pm 1 standard deviation; $\mathrm{N}=10$ ). Aeration was not provided so each flask was swirled once daily by hand. Once the cultures had reached late-log phase (13-15 days post-inoculation) cell density and the percentage of each morphotype in the algal population were determined for each culture as above. Five cultures were enriched for ovals and five for fusiforms and the experiment was repeated for a second batch of flasks to give a total of 20 cultures.

\section{Preparation of cell extracts}

Algal cells were harvested from each culture by centrifugation ( $3600 g ; 15$ minutes; $4^{\circ} \mathrm{C}$ ) and the supernatants discarded. The resulting cell pellets were stored at $-80^{\circ} \mathrm{C}$ until extraction. The frozen pellets were thawed, washed once in $1 \mathrm{ml}$ sterile $3.2 \% \mathrm{NaCl}$ and after centrifugation $(12,000 \mathrm{~g} ; 2$ minutes; $20^{\circ} \mathrm{C}$ ) were re-suspended in $0.6 \mathrm{ml}$ methanol:water (5:1). The cells were lysed by sonication on ice for 2 minutes (active:passive interval 0.6:0.4 seconds) with a Status US 200 ultrasonicator fitted with a $\emptyset_{2} \mathrm{~mm}$ probe (Philip Harris Scientific, Lichfield, Staffs, UK). Lysates were kept on ice and agitated on an orbital mixer (180 rpm; 1 hour) before removal of cell 
debris by centrifugation $\left(12,000 g ; 1\right.$ hour; $\left.4^{\circ} \mathrm{C}\right)$. The supernatants were aspirated and dried by vacuum centrifugation for $\sim_{4}$ hours at $30^{\circ} \mathrm{C}$ (GL11 Gyrovap; Philip Harris Scientific, Lichfield, Staffs, UK). Before use, the dried extracts from the mixed morphotype cultures were reconstituted to $60 \mathrm{mg} \mathrm{ml}^{-1}$ in sterile $50 \mathrm{mM}$ HEPES buffer $\mathrm{pH} 7.8$ (Acros Organics, Geel, Belgium). The extracts from the enriched morphotype cultures were similarly reconstituted in $50 \mathrm{mM}$ HEPES but to a concentration where each $1 \mu \mathrm{l}$ contained extract from $7.5 \times 10^{6}$ cells.

\section{Radial diffusion assay for antibacterial activity}

Antibacterial activity in each of the methanol extracts was determined by a two-layer radial diffusion assay (RDA) modified from Lehrer et al. (1991). Briefly, $15 \mathrm{ml}$ of tenth nutrient strength Luria-Bertani (LB) broth was supplemented with agar powder to a final concentration $0.6 \% \mathrm{w} / \mathrm{w}$. After autoclaving and cooling to $\sim 40^{\circ} \mathrm{C}$ the agar was inoculated with $1 \times 10^{7}$ cfu of exponential-phase Staphylococcus aureus. The bacterium had been cultured overnight in LB medium at $37^{\circ} \mathrm{C}$, harvested by centrifugation $\left(2060 \mathrm{~g} ; 10\right.$ minutes; $\left.4^{\circ} \mathrm{C}\right)$, washed twice with $10 \mathrm{ml} 0.9 \% \mathrm{NaCl}$ solution and concentration determined by absorbance at $570 \mathrm{~nm}$, against a blank of $0.9 \% \mathrm{NaCl}$. Each $15 \mathrm{ml}$ volume of inoculated agar was poured into a sterile square Petri dish $(120 \times 120 \mathrm{~mm})$ and allowed to solidify at room temperature. Each plate was then chilled to $4{ }^{\circ} \mathrm{C}$ for 20 minutes. Wells of $3 \mathrm{~mm}$ diameter were bored into the agar using sterile plastic Pasteur pipettes and $4 \mu \mathrm{l}$ of test sample was added to each well. HEPES solution was used for the negative controls and ampicillin $\left(5 \mu \mathrm{g} \mathrm{ml}^{-1}\right)$ was used as the positives. Plates were incubated for 4 hours at $4{ }^{\circ} \mathrm{C}$ to allow the samples to diffuse into the agar. Growth of the bacterium in this base layer was supported by the addition of $15 \mathrm{ml}$ of molten $\left(\sim 40^{\circ} \mathrm{C}\right)$ sterile full-nutrient-strength $\mathrm{LB}$ agar (0.6\% $\mathrm{w} / \mathrm{w}$ agar) as a top layer. Once set the plate was incubated for 24 hours at $37^{\circ} \mathrm{C}$. Zones of growth inhibition were fixed and made more conspicuous by staining for 16 hours with $20 \mathrm{ml}$ stain. This stain contained $20 \mathrm{mg}$ Coomassie brilliant blue reagent (G-250; Pierce, Rockford, IL, USA) that was made up in $210 \mathrm{ml}$ methanol, $630 \mathrm{ml}$ water and $150 \mathrm{ml} 37 \%$ formaldehyde. The diameter of each clear zone was measured to the nearest half millimetre. The area of bacterial growth inhibition was calculated as total area of clear zone minus the area of the well. The antibacterial activity per cell was calculated from the clear zone area and the number of cells known to have contributed to each sample.

\section{Fatty acid analysis}

Fifty microlitres of the methanol extracts prepared from each of enriched oval or fusiform culture were used for gas-liquid chromatography (GLC) analyses to identify and quantify the fatty acids present. First, $50 \mu \mathrm{g}$ of an internal standard (the saturated fatty acid 23:0) was added to each cell extract. Fatty acid methyl esters (FAMEs) were prepared by dissolving each extract in $1 \mathrm{ml}$ toluene. To this was added $2 \mathrm{ml} 1 \%$ sulphuric acid in methanol before overnight incubation in a stoppered tube flushed with nitrogen at $50^{\circ} \mathrm{C}$. Next day, $2 \mathrm{ml}$ of $2 \%$ potassium bicarbonate solution were added. The FAMEs were extracted twice with $3 \mathrm{ml}$ hexane:diethyl ether (1:1) and the upper layers collected by Pasteur pipette and combined. The samples were washed with $4 \mathrm{ml}$ water and any residual water was removed by mixing with anhydrous sodium sulphate. The solutions were then filtered through non-absorbent cotton wool (pre-washed with diethyl ether) and the solvent removed by gentle warming under a stream of nitrogen. The resulting FAMEs were re-dissolved in $0.3 \mathrm{ml}$ hexane and then analysed on a gas chromatograph (Trace GC-2000; ThermoQuest Ltd, Waltham, MA, USA) equipped with a flame-ionization detector fitted with a $\mathrm{DB}_{23}$ fused silica capillary column $(25 \mathrm{~m} \times 0.25 \mathrm{~mm}$ internal diameter; SGE Ltd, Milton Keynes, Bucks, UK). The samples were applied by split injection with hydrogen as the carrier gas. Oven temperature started at $60^{\circ} \mathrm{C}$ for 2 minutes, increased to $150^{\circ} \mathrm{C}$ at $20^{\circ} \mathrm{C}$ $\min ^{-1}$, held for 2 minutes, then increased to $205^{\circ} \mathrm{C}$ at $1.8^{\circ} \mathrm{C}$ $\min ^{-1}$, then finally increased to $230^{\circ} \mathrm{C}$ at $5^{\circ} \mathrm{C}$ minutes ${ }^{-1}$. Reference FAME mixtures were also analysed and separated FAMEs were identified by comparison. The relative percentage by weight of each FAME in the extracts was calculated and the mass of each FAME per cell was then derived.

\section{Statistical analyses}

All statistical tests were performed using SPSS v. 15.0 for Windows (SPSS Inc., Chicago, IL, USA). The antibacterial activities of the extracts obtained from the fifty-one $470 \mathrm{ml}$ cultures in the first experiment were plotted against the percentage of fusiform cells in that culture. Because the data was not normally distributed (Shapiro-Wilk test: $W_{51}=$ o.866, $P<0.001$ ) Spearman's rank-order correlation was used to analyse the correlation.

A two-way analysis of variance (ANOVA) (with batch and morph as factors) was used to test for a significant difference between the antibacterial activity attributable to each cell in the oval-enriched compared to the fusiform-enriched cultures. Principal components analysis (PCA) was performed on the relative FAME composition of the cell extracts from these morph-enriched cultures. Two-way ANOVA (with batch and morph as factors) were used to test for significant differences in the FAME composition of extracts from the morph-enriched cultures in: (i) the relative percentage of each FAME; and (ii) calculated mass of each FAME per cell. Only FAMEs composing $\sim 1 \%$ or more in the extracts were considered and before analyses the relative composition data were transformed by the arcsine square root function. Type I errors in these multiple analyses were reduced by enforcing the highly stringent Bonferroni correction. Two-way ANOVA (again with batch and morph as factors) were also used to test for significant differences in: (i) summed relative composition of EPA, HTA and PA; (ii) total mass of FAMEs; and (iii) summed mass of EPA, HTA and PA in the extracts from the morph-enriched cultures when calculated on a per cell basis. In most cases data were normally distributed and showed equal variances when tested by Shapiro-Wilk and Levene's tests, respectively. In all tests $P<0.05$ was considered significant.

\section{RESULTS}

\section{Antibacterial activities}

The methanol extracts from the 51 mixed morphology cultures of Phaeodactylum tricornutun showed a highly 
significant positive correlation $(\rho=0.487, \mathrm{~N}=51, P<0.01)$ between the antibacterial activity against Staphylococcus aureus and the percentage of fusiform cells in the extracted culture, after normalizing for cell number by calculating activity as units per cell (Figure 1 ). Conversely there was a significant negative correlation $(\rho=-0.332, \mathrm{~N}=51, P<0.05)$ between antibacterial activity and the percentage of cells found as ovals in the extracted culture, again with activity calculated on a per cell basis (data not shown). Similar significant correlations were seen for these extracts when tested against Micrococcus luteus NCIMB9278, Planococcus citreus NCIMB1493 and Pseudomonas aeruginosa NCIMB10775 (data not shown). No triradiate cells were detected in the samples taken for cell enumeration, so it was assumed that this morphotype was absent or at a concentration too low to make a significant contribution to the data. The correlation between the proportion of each morphotype in a culture and the antibacterial activity of methanol extracted cell constituents indicates that not only does antibacterial activity vary between cultures but also that the fusiform cells tend to display greater activity than the ovals.

The antibacterial activity attributable to each cell in the fusiform-enriched cultures was $6.50 \times 10^{-6} \mathrm{~mm}^{2}$ (Figure 2). By contrast antibacterial activity in the cultures containing $100 \%$ oval cells was calculated to be $3.44 \times$ $10^{-6} \mathrm{~mm}^{2}$ per cell (Figure 2), which is significantly lower $(P<0.05)$ than the value obtained per cell in the fusiformenriched cultures. These data confirm that fusiform cells contain greater antibacterial activity against $S$. aureus in their extracts than oval cells. It is not clear why it was possible to enrich for either morphotype under identical culture conditions but this phenomenon has been reported by other workers (Lewin et al., 1958; Darley, 1968; Johansen, 1991; De Martino et al., 2007).

\section{Fatty acid composition of extracts from cultures enriched for fusiform or oval cells}

Relative fatty acid composition was determined for the extracts from cultures enriched for fusiform or oval cells.

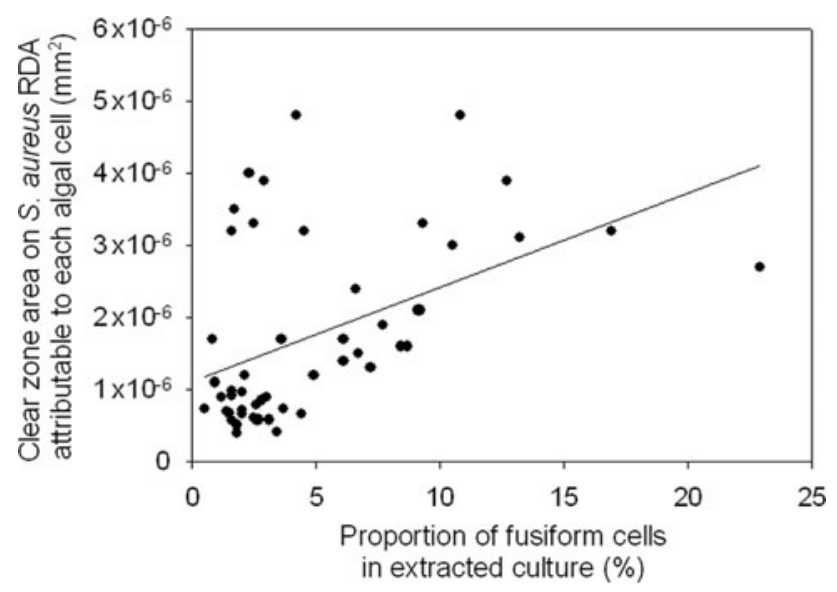

Fig. 1. Antibacterial activity against Staphylococcus aureus attributable to each cell in extracts prepared from Phaeodactylum tricornutum cultures containing a mixture of fusiform and oval cells. Extracts prepared from cultures containing greater proportions of fusiform cells correlated significantly $(P<$ 0.01 ) and positively with the antibacterial activity attributable to each cell in those extracts.

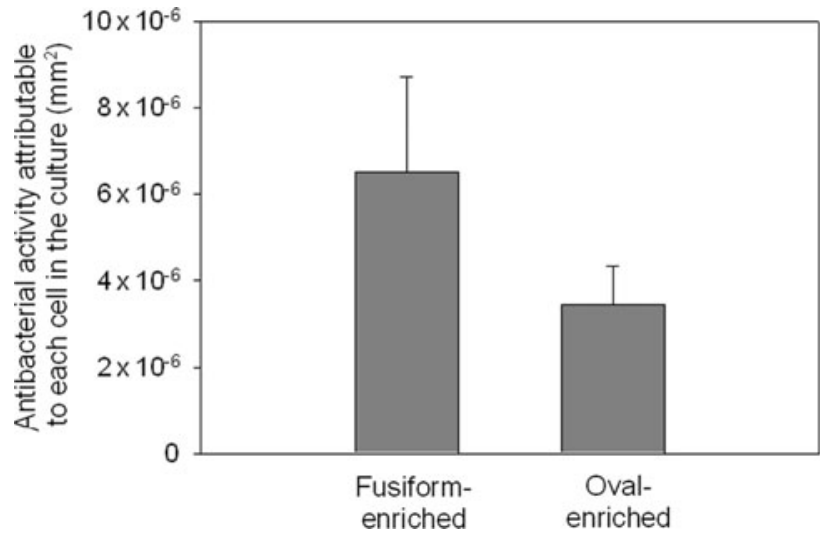

Fig. 2. Antibacterial activity against Staphylococcus aureus attributable to each cell in extracts prepared from cultures enriched in either fusiform or oval cells showing that each cell in the fusiform-enriched cultures had significantly greater antibacterial activity than each cell in the oval-enriched cultures (two-way ANOVA: $F_{3,16}=4.66, P<0.05$ ). $\mathrm{N}=10$; error bars are $\pm 1 \mathrm{SE}$.

The PCA of these data show that the extracts from the enriched cultures grouped into two distinct populations corresponding to those prepared from oval- and fusiform-enriched cultures (Figure 3). Further statistical examination of the relative composition data by two-way ANOVA confirm that the extracts from cultures enriched for fusiform or oval cells differed significantly $(P<0.05$; Bonferroni correction $)$ in the relative amounts of seven fatty acids, namely $\mathrm{C}_{14}$ :0, C16:0, C16:2 n-4, C16:3 n-4 (HTA), C16:4 n-1, C20:4 n-6 and C20:6 n-3 (Table 1).

The relative composition data were used to calculate the mass of each FAME attributable to each cell in every extract. These data show that extracts prepared from cultures enriched for the fusiform morphotype contain significantly greater $\left(P<0.05\right.$; Bonferroni correction) masses of $\mathrm{C}_{14}$ :0, C16:2 n-4 and C16:3 n-4 (HTA) attributable to each cell compared with the oval-enriched cultures (Table 2). Moreover, the total mass of FAMEs attributable to each cell in the cultures

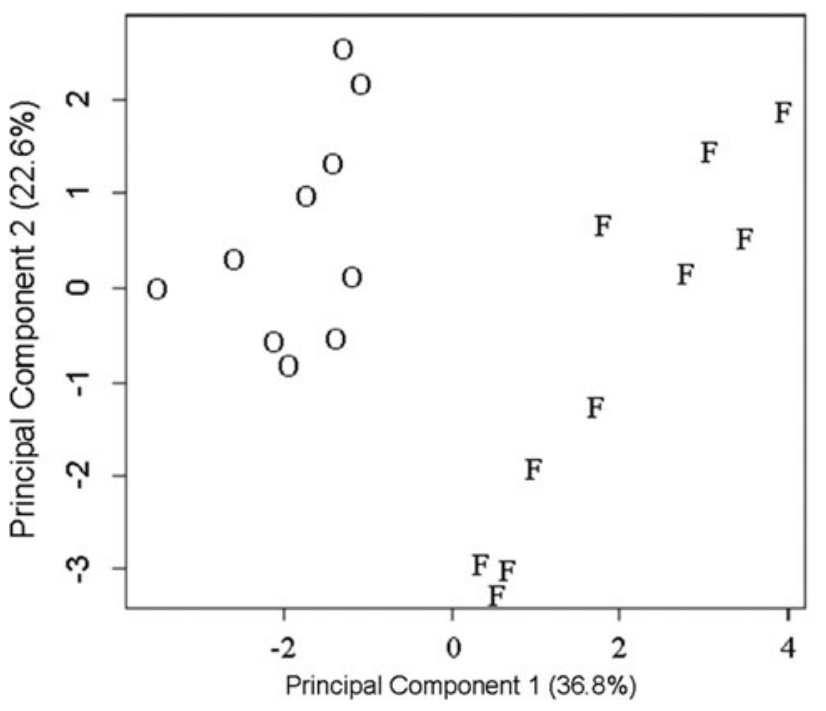

Fig. 3. Plot of first two principal components of 13 fatty acids in methanol cell extracts prepared from Phaeodactylum tricornutum cultures enriched for either the oval (O) or fusiform (F) morphotype. First and second components accounted for $36.8 \%$ and $22.6 \%$ of the total variance, respectively, $\mathrm{N}=20$. 
Table 1. Relative percentage of each fatty acid in methanol cell extracts from enriched cultures containing either $>71 \%$ fusiform cells or $100 \%$ oval cells showing that cells in the fusiform-enriched cultures contain significantly greater proportions of C14:0, C16:2 n-4, C16:3 n-4 and C16:4 n-1 $(P<0.05$; Bonferroni correction) but significantly lower proportions of $\mathrm{C}_{1} 6: 0, \mathrm{C}_{20} \mathrm{0} 4 \mathrm{n}-6$ and $\mathrm{C}_{20} \mathrm{0:6} \mathrm{n}-3$ ( $P<0.05$; Bonferroni correction). Extracts from enriched cultures did not differ significantly in the sum proportion of the three antibacterial fatty acids (EPA, HTA and PA) isolated from similar extracts in previous studies (Desbois et al., 2008, 2009). *, significant difference between the two cell types.

\begin{tabular}{lrr}
\hline Fatty acid & \multicolumn{2}{c}{$\begin{array}{l}\text { Relative percentage of each fatty acid } \\
\text { in cell extracts }\end{array}$} \\
\cline { 2 - 3 } & \multicolumn{1}{c}{ Fusiform } & \multicolumn{1}{c}{ Oval } \\
\hline C14:0* & $7.89 \pm 0.37$ & $6.39 \pm 0.28$ \\
C16:0* & $9.59 \pm 1.32$ & $10.70 \pm 1.45$ \\
PA/C16:1 n-7 & $21.04 \pm 1.99$ & $21.72 \pm 1.02$ \\
C16:2 n-4* & $4.26 \pm 0.44$ & $1.92 \pm 0.23$ \\
HTA/C16:3 n-4* & $10.15 \pm 1.52$ & $9.10 \pm 0.69$ \\
C16:4 n-1* & $0.66 \pm 0.10$ & $0.41 \pm 0.30$ \\
C18:1 n-9 & $2.66 \pm 0.76$ & $3.58 \pm 1.21$ \\
C18:2 n-6 & $1.95 \pm 0.23$ & $2.02 \pm 0.56$ \\
C18:3 n-6 & $1.23 \pm 0.19$ & $1.21 \pm 0.10$ \\
C18:4 n-3 & $0.64 \pm 0.09$ & $0.70 \pm 0.15$ \\
C20:4 n-6* & $1.22 \pm 0.13$ & $1.74 \pm 0.24$ \\
EPA/C20:5 n-3 & $36.60 \pm 2.36$ & $37.79 \pm 1.39$ \\
C20:6 n-3 & $2.12 \pm 0.16$ & $2.71 \pm 0.19$ \\
Sum (PA, HTA, EPA) & $68.61 \pm 2.04$ & $67.79 \pm 2.06$ \\
\hline
\end{tabular}

$\mathrm{N}=10$; data given as mean $\pm 1 \mathrm{SD}$ to two decimal places.

enriched with fusiform cells is significantly greater $(P<0.05)$ than compared to oval-enriched cultures (Table 2). In addition, the summed mass of FAME of the three antibacterial fatty acids (EPA, HTA and PA) attributable to each cell was

Table 2. Mass of fatty acids attributable to each cell in methanol cell extracts from cultures enriched to contain either $>71 \%$ fusiform cells or $100 \%$ oval cells showing that cells in the fusiform-enriched cultures contained significantly greater masses of $\mathrm{C}_{14}: 0, \mathrm{C}_{16: 2} \mathrm{n}-4$ and $\mathrm{C}_{16} 6: 3$ n-4 $(P<0.05 ;$ Bonferroni correction $)$. Moreover, extracts from fusiform-enriched cultures contained a significantly greater mass of fatty acids in total $(P<0.05)$, as well as a significantly greater total mass of three antibacterial fatty acids (EPA, HTA and PA) isolated from similar extracts previously $\left(P<0.05\right.$; Desbois et al., 2008, 2009). ${ }^{*}$, significant difference between the two cell types.

\begin{tabular}{lcc}
\hline Fatty acid & \multicolumn{2}{l}{$\begin{array}{l}\text { Mass of fatty acid attributable to each } \\
\text { cell }\left(\mathbf{g} \times \mathbf{1 0}^{-\mathbf{1 3}}\right)\end{array}$} \\
\cline { 2 - 3 } & Fusiform & Oval \\
\hline C14:0* & $5.04 \pm 0.675$ & $3.47 \pm 0.651$ \\
C16:0 & $6.35 \pm 0.998$ & $6.17 \pm 1.31$ \\
PA/C16:1 n-7 & $13.7 \pm 2.04$ & $11.5 \pm 2.04$ \\
C16:2 n-4* & $2.69 \pm 0.376$ & $1.10 \pm 0.228$ \\
HTA/C16:3 n-4* & $6.14 \pm 0.578$ & $4.78 \pm 0.847$ \\
C16:4 n-1 & $0.435 \pm 0.069$ & $0.304 \pm 0.094$ \\
C18:1 n-9 & $1.80 \pm 0.337$ & $1.82 \pm 0.317$ \\
C18:2 n-6 & $1.23 \pm 0.160$ & $1.16 \pm 0.276$ \\
C18:3 n-6 & $0.784 \pm 0.110$ & $0.660 \pm 0.127$ \\
C18:4 n-3 & $0.414 \pm 0.065$ & $0.386 \pm 0.074$ \\
C20:4 n-6 & $0.773 \pm 0.098$ & $0.894 \pm 0.152$ \\
EPA/C20:5 n-3 & $22.8 \pm 2.68$ & $20.3 \pm 3.78$ \\
C20:6 n-3 & $1.37 \pm 0.191$ & $1.49 \pm 0.290$ \\
PA + HTA + EPA* & $42.7 \pm 5.29$ & $36.6 \pm 6.66$ \\
Total mass (all FAME) & $63.5 \pm 8.24$ & $54.0 \pm 10.1$ \\
\hline
\end{tabular}

$\mathrm{N}=10$; data given as mean $\pm 1 \mathrm{SE}$ to three significant figures. significantly greater $(P<0.05)$ in cultures enriched in fusiform cells compared with oval-enriched cultures (Table 2).

\section{DISCUSSIDN}

The two main Phaeodactylum tricornutum morphotypes (fusiform and oval) culturable under our laboratory set-up differ not only in their shape, buoyancy and motility but also in their lipid dry weight (34 and $24 \%$, respectively), protein dry weight ( $41 \%$ and $34 \%$ respectively) and exopolysaccharide content $\left(<_{1} \%\right.$ and $16 \%$ respectively) (Lewin et al., 1958; Iwasa \& Shimizu, 1972). Carbohydrate and ash levels are similar but the oval cell surface expresses very different immunogenetic epitopes to the fusiform cell (Lewin et al., 1958; Gutenbrunner et al., 1994). The present study now shows that extracts from fusiform cells contain a greater quantity than the ovals of the fatty acids, EPA, HTA and PA, (42.7 and $36.6 \times 10^{-13} \mathrm{~g}$, respectively). These are known to have strong antibacterial activity against our test bacterium, Staphylococcus aureus, as well as various marine bacteria (Desbois et al., 2008, 2009). Greater quantities of antibacterial free fatty acids in the extracts from fusiform cells may be due to fusiform cells containing more lipid as a proportion of cell composition than the oval cells or alternatively, the fusiform cells may be more fragile due to their shape and cell wall structure compared with the oval cell, which is more siliceous and rigid (Lewin et al., 1958; Borowitzka \& Volcani, 1978; Francius et al., 2008).

It is known that free fatty acids are released from algal cells by enzyme action when the cells lose their structural integrity (Jüttner, 2001; Pohnert, 2002). This has been suggested as an 'activated defence' mechanism to protect an algal population against grazing predators at the expense of a small number of individuals (Jüttner, 2001). Free fatty acids could also act against surrounding pathogenic bacteria when the structural integrity of the cells is breached, for example during microbial attack. Thus, the free fatty acids kill the pathogen and prevent it infecting adjacent microalgal cells. As cell extracts from fusiform cells contain greater amounts of these fatty acids, it is reasonable to conclude that they provide greater potential protection for the fusiform cells compared with oval cells. We suggest that the release of free fatty acids from cell lipids after cell damage is a low-cost, activated, population-level defence strategy against not only grazing predators but also pathogenic bacteria.

\section{ACKNOWLEDGEMENTS}

This work was funded by a BBSRC studentship (BBS/S/ $\mathrm{M} / 2003 / 10490$ ) with additional support from Aquapharm Bio-Discovery Ltd (Oban, Argyll, UK). The experiments described were performed during the period 2004 to 2006.

\section{REFERENCES}

Bartual A., Angel Gálvez J. and Ojeda F. (2008) Phenotypic response of the diatom Phaeodactylum tricornutum Bohlin to experimental changes in the inorganic carbon system. Botanica Marina 51, $350-359$. 
Borowitzka M.A., Chiappino M.L. and Volcani B.E. (1977) Ultrastructure of a chain-forming diatom Phaeodactylum tricornutum. Journal of Phycology 13, 162-170.

Borowitzka M.A. and Volcani B.E. (1978) The polymorphic diatom Phaeodactylum tricornutum: ultrastructure of its morphotypes. Journal of Phycology 14, 10-21.

Bowler C. et al. (2008) The Phaeodactylum genome reveals the evolutionary history of diatom genomes. Nature 456, 239-244.

Cole J.J. (1982) Interactions between bacteria and algae in aquatic ecosystems. Annual Review of Ecological Systems 13, 291-314.

Coughlan J. (1962) Chain formation by Phaeodactylum. Nature 195 $831-832$.

Darley W.M. (1968) Deoxyribonucleic acid content of the three cell types of Phaeodactylum tricornutum Bohlin. Journal of Phycology 4, 219-220.

De Martino A., Meichenin A., Shi J., Pan K. and Bowler C. (2007) Genetic and phenotypic characterization of Phaeodactylum tricornutum (Bacillariophyceae) accessions. Journal of Phycology 43 $992-1009$.

Desbois A.P., Mearns-Spragg A. and Smith V.J. (2009) A fatty acid from the diatom Phaeodactylum tricornutum is antibacterial against diverse bacteria including multi-resistant Staphylococcus aureus (MRSA) Marine Biotechnology 11, 45-52.

Desbois A.P., Yan L., Lebl T. and Smith V.J. (2008) Isolation and structural characterisation of two antibacterial free fatty acids from the marine diatom, Phaeodactylum tricornutum. Applied Microbiology and Biotechnology 81, 755-764.

Duff D.C.B., Bruce D.L. and Antia N.J. (1966) The antibacterial activity of marine planktonic algae. Canadian Journal of Microbiology 12 $877-884$

Francius G., Tesson B., Dague E., Martin-Jézéquel V. and Dufrêne Y.F (2008) Nanostructure and nanomechanics of live Phaeodactylum tricornutum morphotypes. Environmental Microbiology 10, 1344-1356.

Gutenbrunner S.A., Thalhamer J. and Schmid A.-M.M. (1994) Proteinaceous and immunochemical distinctions between the oval and fusiform morphotypes of Phaeodactylum tricornutum (Bacillariophyceae). Journal of Phycology 30, 129-136.

Hamm C.E., Merkel R., Springer O., Jurkojc P., Maier C., Prechtel K. and Smetacek V. (2003) Architecture and material properties of diatom shells provide effective mechanical protection. Nature 421 , $841-843$.

Harrison P.J., Waters R.E. and Taylor F.J.R. (1980) A broad spectrum artificial seawater medium for coastal and open ocean phytoplankton. Journal of Phycology 16, 28-35.

Hayward J. (1968) Studies on the growth of Phaeodactylum tricornutum. Journal of the Marine Biological Association of the United Kingdom 48, $657-666$.

Imai I., Ishida Y. and Hata Y. (1993) Killing of marine phytoplankton by a gliding bacterium Cytophaga sp., isolated from the coastal Sea of Japan. Marine Biology 116, 527-532.
Iwasa K. and Shimizu A. (1972) Motility of the diatom, Phaeodactylum tricornutum. Experimental Cell Research 74, 552-558.

Johansen J.R. (1991) Morphological variability and cell wall composition of Phaeodactylum tricornutum (Bacillariophyceae). Great Basin Naturalist 51, 310-315.

Jüttner F. (2001) Liberation of 5,8,11,14,17-eicosapentaenoic acid and other polyunsaturated fatty acids from lipids as a grazer defense reaction in epilithic diatom biofilms. Journal of Phycology 37, 744-755.

Kellam S.J. and Walker J.M. (1989) Antibacterial activity from marine microalgae in laboratory culture. British Phycological Journal 24, $191-194$.

Lehrer R.I., Rosenman M., Harwig S.S.S.L., Jackson R. and Eisenhauer P. (1991) Ultrasensitive assays for endogenous antimicrobial polypeptides. Journal of Immunological Methods 137, 167-173.

Lewin J.C., Lewin R.A. and Philpott D.E. (1958) Observations on Phaeodactylum tricornutum. Journal of General Microbiology 18, $418-426$.

Marsot P. and Houle L. (1989) Excrétion cellulaire et morphogénèse de Phaeodactylum tricornutum (Bacillariophyceae). Botanica Marina $32,355-367$.

Mayali X. and Azam F. (2004) Algicidal bacteria in the sea and their impact on algal blooms. Journal of Eukaryotic Microbiology 51, $139-144$.

Morales E.A., Trainor F.R. and Schlichting C.D. (2002) Evolutionary and ecological implications of plastic responses of algae. Constancea 83. Last accessed 4 November 2008. [http://ucjeps.berkeley.edu/ constancea/83/morales_etal/plasticity.html]

Pohnert G. (2002) Phospholipase A2 activity triggers the wound-activated chemical defense in the diatom Thalassiosira rotula. Plant Physiology $129,103-111$.

Reynolds C.S. (2007) Variability in the provision and function of mucilage in phytoplankton: facultative responses to the environment. Hydrobiologia 578, 37-45.

Tesson B., Gaillard C. and Martin-Jézéquel V. (2009) Insights into the polymorphism of the diatom Phaeodactylum tricornutum Bohlin. Botanica Marina 52, 104-116.

and

Wilson D.P. (1946) The triradiate and other forms of Nitzschia closterium (Ehrenberg) Wm. Smith, forma minutissima of Allen and Nelson. Journal of the Marine Biological Association of the United Kingdom $26,235-270$.

\section{Correspondence should be addressed to:}

V.J. Smith

Scottish Oceans Institute

Gatty Marine Laboratory

School of Biology

University of St Andrews

Fife, Scotland, UK

email: vjs1@st-andrews.ac.uk 